\title{
ЭКОЛОГИЯ
}

И ПРИРОДОПОЛЬЗОВАНИЕ

DOI: https://doi.org/10.15688/jvolsu11.2017.4.4

UDC 504.062.12

LBC $26.23+67.401$ я73 M 69

\section{ON THE INFLUENCE OF INDUSTRIAL ENTERPRISES \\ ON POLLUTION OF THE MILK DIVERSIBLE DUST \\ OF THE RESIDENTIAL TERRITORIES OF THE CITY}

\author{
Katerina A. Trokhimchuk \\ Volgograd State University, Volgograd, Russian Federation
}

\begin{abstract}
The article discusses the effect of industrial enterprises on the contamination by fine dust of residential areas in the city. The results of studies on the concentration of suspended dust particles with a size of less than $10 \mathrm{~mm}$ and less than $2.5 \mathrm{Mm}$ in the production zone having ash dumps and in a residential area near the industrial enterprise are presented. In the residential area, near the industrial enterprise there is an increased content of fine dust. It is proposed to use the dust collection machine developed by the author to protect the environment on the territory of the enterprise and the housing estate, the action of which is aimed at reducing dust from the production facility. The dust collector allows not only daily cleaning of the areas of the enterprise, city territories, but also is effective after construction and repair-emergency works. The machine has increased maneuverability. It allows to clean up the territory in the cramped conditions of the industrial site, in the areas of compacted buildings. The dust collector can be used after construction, digging trenches and pits, near the ash dumps and man-made development.
\end{abstract}

Key words: fine dust, ash dumps, dust collecting machine, residential area.

УДК 504.062.12

ББК 26.23+67.401 я73 М 69

\section{О ВЛИЯНИИ ПРОМЫШЛЕННЫХ ПРЕДПРИЯТИЙ НА ЗАГРЯЗНЕННОСТЬ МЕЛКОДИСПЕРСНОЙ ПЫЛЬЮ ЖИЛЫХ ТЕРРИТОРИЙ ГОРОДА}

\footnotetext{
Катерина Алексеевна Трохимчук 


\section{ЭКОЛОГИЯ И ПРИРОДОПОЛЬЗОВАНИЕ}

шина позволяет выполнять не только ежедневную качественную уборку зон предприятия, городских территорий, а также эффективна после проведения строительных и ремонтно-аварийных работ. Машина обладает повышенной маневренностью. Позволяет производить уборку территории в стесненных условиях промышленной площадки, на участках уплотненной застройки.

Ключевые слова: Мелкодисперсная пыль, золоотвалы, пылеуборочная машина, жилая зона.

Постановка проблемы. Многие города в своей планировке включают размещение промышленных предприятий рядом с жилыми кварталами, что связано с необходимостью размещения рабочих радом с местом работы. В настоящее время такие населенные пункты, не редко, попадают в санитарнозащитные зоны предприятий [12]. За последнее время среди жителей таких районов участились заболевания, которые присущи работникам промышленности (бронхит пылевой этиологии, пневмокониоз, дерматозы, кохлеарный неврит и др.) [2, 14, 18-21]. Причиной сложившейся обстановки можно считать отсутствие контроля содержания пыли в зонах проживания. Если на самих предприятиях для защиты рабочих предусмотрено использование средств защиты от воздействия пыли и осуществляется контроль качества воздуха рабочей территории $[3-6,15]$, то на территории жилой застройки подобный мониторинг проводится не регулярно. Поэтому исследования запыленности населенных пунктов, расположенных вблизи промышленных площадок, являются актуальной задачей.

Теоретический анализ. Современные научные разработки показывают [2, 13, 14, 17], что почти во всех случаях возникновения острых и хронических заболеваний дыхательных путей возрастание доли мелкодисперсных частиц размером менее 2,5 мкм оказывало более существенное влияние на уровень смертности, чем возрастание доли частиц размером 10 мкм. Частицы с аэродинамическим диаметром 10 мкм, прошедшие при отборе проб на анализ через селективный импактор (приспособление, обеспечивающее 50 \% задержку частиц диаметром 10 мкм), относят к PM10. Частицы с аэродинамическим диаметром 2,5 мкм относят к РМ2,5. Верхний предел полного отсеивания соответствует 7 мкм.

В настоящее время в России введены в действие Гигиенические нормативы ГН 2.1.6.2604-10 «Предельно допустимые концентрации (ПДК) загрязняющих веществ в ат- мосферном воздухе населенных мест», которые с 21 июня 2010 г. устанавливают предельно допустимую концентрацию (ПДК) загрязняющих веществ в атмосферном воздухе населенных мест в мг $/ \mathrm{M}^{3}$ для взвешенных частиц размером менее 10 мм (среднесуточная величина ПДК равна $\left.0,06 \mathrm{мг} / \mathrm{M}^{3}\right)$ и для частиц размером менее 2,5 мкм (среднесуточная величина ПДК равна $\left.0,035 \mathrm{m \Gamma} / \mathrm{M}^{3}\right)$ [1].

Методика эксперимента. Для исследования дисперсного состава пыли предлагается использование методики микроскопического анализа с применением ПК, которая позволяет оценить характер мелкодисперсной пыли [2]. Методика предназначена для измерений дисперсного состава пылевидных частиц путем разностороннего фотографирования через микрофотоприставку, полученных с исследованного объекта образцов, увеличенных под микроскопом в 200-2000 раз. Количество необходимых фотографий зависит от полидисперсности пыли. Снятие изображения с фотоаппарата и последующая обработка производится с помощью графического пакета Adobe PhotoShop. Для цифровой обработки чернобелых изображений используется программный продукт «SPOTEXPLRER V1.0», позволяющий: выявить форму пылевидных частиц, коэффициент их сферичности; построить интегральные функции распределения частиц по эквивалентным диаметрам.

В качестве объекта для исследования был выбран ряд промпредприятий России, имеющих золоотвалы. Проведены исследования по содержанию концентраций РМ10 и PM2,5 в производственной зоне промышленного предприятия, в жилой зоне, находящейся в километровой зоне от предприятия и в приусадебной зоне, расположенной в 500 м от промышленной зоны. Были отобраны пробы на источнике пыления (золоотвал), в застроенном микрорайоне и в зоне приусадебных территорий. Результаты исследования концентрации пыли при скорости ветра 3-5 м/с сведены в таблице 1. 
К.A. Трохимчук. О влиянии промышленных предприятий на загрязненность мелкодисперсной пылью

Получено, что наибольший процент выноса пыли с золоотвалов зависит от влажности элементов, слагающих золоотвал, и размера отвала (массы).

Анализ полученных результатов. Результаты исследований показали, что на расстоянии в зоне 1 км от золоотвала при ветре 2,5 м/с запыленность составляет 0,15-0,30, что не превышает нормы. При скорости ветра до 5 м/с показатели запыленности возрастают. На расстоянии 50 м от золоотвала РМ10 составляет приблизительно 50 \%, а РМ2,5 около 10-20\%; на расстоянии 500 м от золоотвала РМ10 составляет более 30 \%, а РМ2,5 достигает $30 \%$, то есть ветер способен переносить мелкодисперсную пыль на значительные расстояния. В жилой зоне вблизи про- мышленного предприятия, расположенной, как правило, за пределами 50 метровой отметки отмечается повышенное содержание мелкодисперсной пыли.

Предлагается на таких участках использовать разработанную автором пылеуборочную машину, отличающуюся от известных ранее $[7$, с. $1-3 ; 8$, с. $1-5 ; 9$, с. $1-4$; 10 , с. 1-6; 16, с. 234-286] тем, что она содержит пылегазовый аэродинамический узел, способствующий снижению выноса пыли в атмосферу городской среды, расширению возможностей по утилизации загрязненных веществ и снижающий ущерб окружающей среде [11, с. 1-6].

Пылегазовый аэродинамический узел пылеуборочной машины (рис. 1) содержит ци-

\section{Результаты замеров концентрации пыли при скорости ветра 3-5 м/с}

\begin{tabular}{|c|c|c|c|}
\hline \multirow{2}{*}{ Точка замера } & \multicolumn{3}{|c|}{ Концентрация пыли, мг/м³ } \\
\hline & Общая & PM 10 & PM 2,5 \\
\hline Вблизи золотвала (2-5 м) & $5,0-15,0$ & $0,9-4,0$ & $0,4-0,8$ \\
\hline На расстоянии 50 м от золоотвала & $0,7-1,9$ & $0,4-0,9$ & $0,07-0,39$ \\
\hline На расстоянии 200 м от золоотвала & $0,5-0,8$ & $0,3-0,4$ & $0,2-0,25$ \\
\hline На расстоянии 500 м от золоотвала & $0,35-0,6$ & $0,25-0,3$ & $0,20-0,22$ \\
\hline На расстоянии 1000 м от золоотвала & $0,1-0,25$ & $0,12-0,18$ & $0,08-0,13$ \\
\hline
\end{tabular}

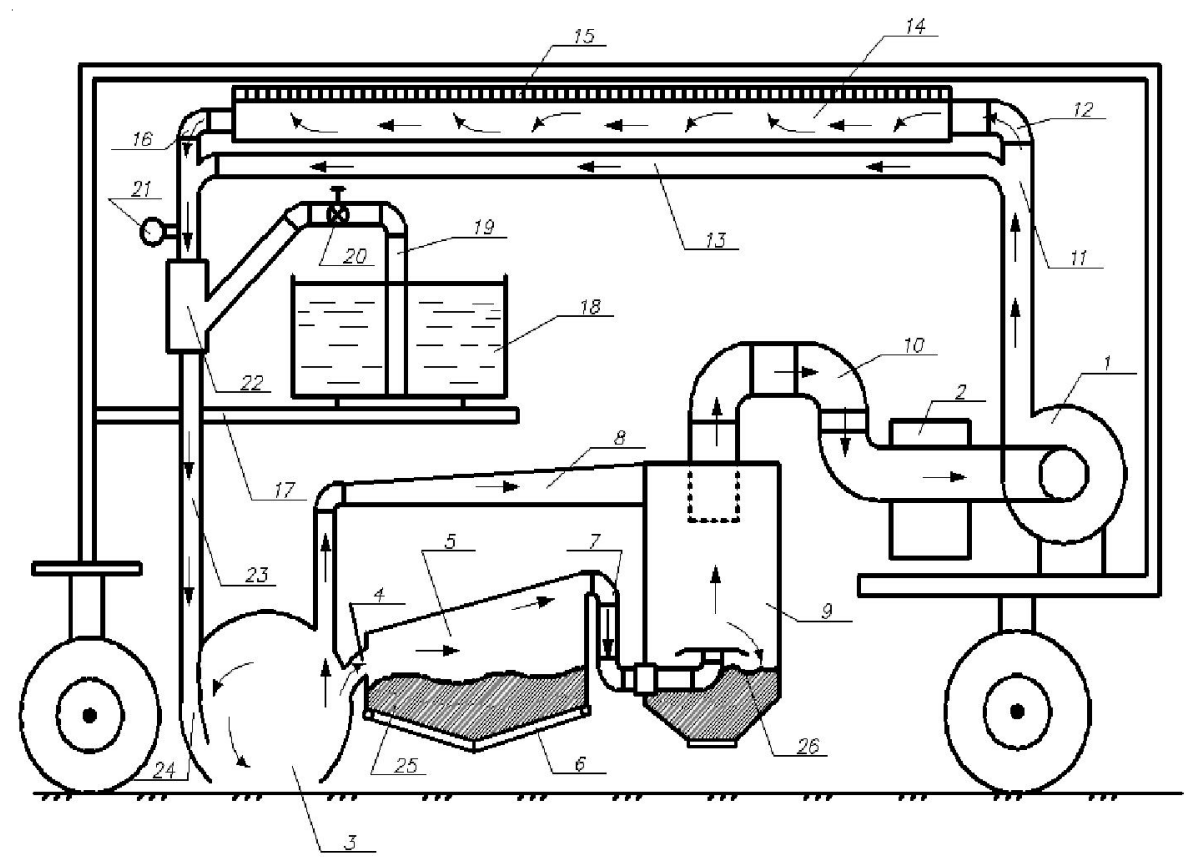

Рис. 1. Общий вид пылегазового аэродинамического узла для пылеуборочных машин:

1 - вентиляторный нагнетатель; 2 - привод; 3 - цилиндрическая вихревая рабочая камера;

4, 7, 8, 10, 13, 16, 23 - ветви; 5 - накопитель; 6- створки накопителя; 9- пылеуловитель; 11 - нагнетательный канал; 14 - фильтрационная камера; 15 - фильтра тонкой очистки; 17, 19 - каналы; 18 - резервуар с пенящейся жидкостью; 20 - вентиль; 21 - датчик пыли; 22 - эжектор; 24 - сопло; 25 - тяжелая фракция; 26 - пылевидная фракция 
линдрическую вихревую рабочую камеру, собирающую загрязняющие вещества с твердых поверхностей, имеет систему патрубков, по которым загрязненная масса попадает в накопитель для концентрации тяжелой фракции, снабжен пылеуловителем для сбора пылевидной фракции (частицы до 5 мм) и фильтрационной камерой с фильтром тонкой очистки. Движение воздушного потока создается вентиляторным нагнетателем с приводом.

Пылегазовый аэродинамический узел для пылеуборочных машин, содержит: вентиляторный нагнетатель воздуха с приводом, цилиндрическую вихревую рабочую камеру с системой патрубков для прохождения рабочего газового потока, накопитель для тяжелой фракции загрязняющих веществ, пылеуловитель для концентрации пылевидной фракции, с возможностью вторичного использования и фильтрационную камеру (см. рис. 1). Причем, пылегазовый аэродинамический узел снабжен резервуаром с пенообразующей жидкостью, для максимального выведения частиц пыли в цилиндрическую вихревую камеру, к тому же он содержит регулирующий датчик пыли, сигнализирующий превышение текущей запыленности фильтруемого воздуха при пяти-двадцати кратной концентрации пыли.

Устройство работает следующим образом. Пылегазовый аэродинамический узел содержит вентиляторный нагнетатель с приводом, который создает воздушный поток, способный с помощью цилиндрической вихревой рабочей камеры захватывать с твердой поверхности загрязняющие вещества и распределять тяжелую фракцию в накопитель, где путем автоматического открытия створок она может удаляться, утилизируясь в последующем как мусор. Пылевидная фракция попадает в пылеуловитель, где после изъятия может использоваться вторично, например, при засыпке котлованов, траншей, устройстве дорожных полотен и других целей строительства.

Воздушный поток, проходя через вентиляторный нагнетатель, попадает в нагнетательный канал и распределяется по двум ветвям. Одна ветвь входит в фильтрационную камеру. Она имеет тангенсальное направление, что позволяет воздушному потоку закручиваться и очищаться с помощью фильтра тонкой очистки. Очищенный воздушный по- ток соединяется с атмосферным воздухом. Другая ветвь выводит загрязненную воздушную массу для дальнейшей очистки. В зоне сочленения этих ветвей установлен датчик пыли, сигнализирующий превышение текущей запыленности фильтруемого воздуха при пятидвадцати кратной концентрации пыли.

Узел снабжен подставкой, где размещен резервуар, который содержит жидкость, попадающую через решетку пенообразователя в выводящий канал. При срабатывании датчика происходит открытие вентиля с подачей пенообразующей жидкости через эжектор, где пенообразующая жидкость способствует увеличению степени очистки воздушной струи. Поток выходит к соплу, сопряженному с входом вихревой рабочей камеры, и вновь, захватывая загрязняющие вещества, он проходит по пылегазовому аэродинамическому узлу, где происходит концентрация тяжелой фракции в накопителе и пылевидной фракции в пылеуловителе.

Использование пылегазового аэродинамического узла позволяет пылеуборочной машине иметь длительный рабочий режим, так как загрязняющие вещества концентрируются в двух элементах: накопителе (тяжелая фракция) и пылеуловителе (пылевидная фракция), утилизация не требует специальных навыков в обслуживании, может происходить во время рабочего процесса.

Пылегазовый аэродинамический узел для пылеуборочных машин способствует: максимальной очистке загрязненной поверхности; позволяет разделять по фракциям загрязняющие вещества, что расширяет возможности их утилизации; уменьшает стоимость по очистке твердых поверхностей; снижает ущерб окружающей среде городской территории и улучшает экологическую обстановку. Использование регулирующего датчика пыли, сигнализирующего превышение текущей запыленности фильтруемого воздуха при пятидвадцати кратной концентрации, позволяет экономить пенообразующую жидкость.

Стоимость рассматриваемой машины составит 3410800 руб. Стоимость аналогичной пылеуборочной машины на мировом рынке составляет 181400 \$. Коэффициент эффективности предлагаемого проекта выражается формулой: 
К.А. Трохимчук. О влиянии промышленных предприятий на загрязненность мелкодисперсной пылью

$$
f_{э \phi}=\frac{K_{p}}{K_{s}} \cdot 100 \%,
$$

где $K_{p}=6530800 / 3987900=1,6-$ плановая стоимость аналога пылеуборочной машины, $K_{в}=6530800 /$ $3410800=1,9-$ плановая стоимость предлагаемой пылеуборочной машины.

Таким образом, получаем, что коэффициент эффективности, вычисленный по (1) составит $f_{э \phi}=1,6 / 1,9 \cdot 100 \%=84 \%$.

Пылеуборочная машина, оснащенная пылегазовым аэродинамическим узлом, позволяет выполнять не только ежедневную качественную уборку зон предприятия, городских территорий, а также эффективна после проведения строительных и ремонтно-аварийных работ. Благодаря компактности машина обладает повышенной маневренностью, что позволит производить очистные работы в стесненных условиях промышленной площадки, на участках уплотненной застройки, широкое ее применение улучшит экологическую составляющую городской агломерации.

\section{Выводы}

1. При оценке загрязнения воздушной среды в жилых массивах не рассматриваются вопросы механизма возникновения и распространения пыли в зависимости характера прилегающего промышленного производства.

2. Проведенные исследования динамики загрязняющих веществ, образующихся с золоотвалов показали, что наибольший процент выноса пыли зависит от влажности элементов, слагающих золоотвал, и размера отвала (массы).

3. В жилой зоне вблизи промышленного предприятия отмечается повышенное содержание мелкодисперсной пыли.

4. Для промышленных и жилых зон предлагается использование пылеуборочной машины, способствующий снижению выноса пыли в атмосферу городской среды и расширению возможностей по утилизации загрязненных веществ.

\section{СПИСОК ЛИТЕРАТУРЫ}

1. Азаров, В. Н. Методика микроскопического анализа дисперсионного состава пыли с приме-

нением персонального компьютера (ПК) / В. Н. Азаров, В. Ю. Юркьян, Н. М. Сергина // Законодательная и прикладная метрология. - 2004. - № 1. - С. 46-48.

2. Белан, Б. Д. Химический состав атмосферного аэрозоля на различных высотах/ Б. Д. Белан, Г. О. Заде, Т. В. Ковалевская // Фотохимические процессы земной атмосферы: Ст. науч. трудов. - М.: Наука, 1990. - С. 5-12.

3. Гигиенические нормативы ГН 2.1.6.2604-10 «Предельно допустимые концентрации (ПДК) загрязняющих веществ в атмосферном воздухе населенных мест». - М. : Минздрав России, 2010.$61 \mathrm{c}$.

4. Методика микроскопического анализа дисперсного состава пыли с применением персонального компьютера. - СПб. : ОАО «НИИ Атмосфеpa», 2013. - C. 15-17.

5. Методика расчета концентраций в атмосферном воздухе вредных веществ, содержащихся в выбросах предприятий: ОНД-86/ Госкомгидромет СССР: Введ. 01.01.87; Взамен СН 369-74. - Л. : Гидрометеоиздат, 1987.- $91 \mathrm{c}$.

6. Методическое пособие по расчету выбросов от неорганизованных источников в промышленности строительных материалов. - Новороссийск : 3АО «НИПИОТСТРОМ», 2002. - 28 с.

7. Пат. на полезную модель РФ № 32787. Машина для уборки дорожных покрытий / Ю. И. Завьялов. - Заявитель и патентообладатель - Общество с ограниченной ответственностью «Планета-К».Заявл.14.05.2003; Опубл. 27.09. 2003. - М. : ФИПС, 2003. - C. 1-3.

8. Пат. РФ № 2147640. Машина для очистки твердых поверхностей / В. А. Закревский, В. Б. Соломянский, Д. М. Ростовцев. - Заявитель и патентообладатель - Научно-производственное товарищество с ограниченной ответственностью «Русская керамика». Заявл. 17.02.1998; Опубл. 20.04.2000.-М. : ФИПС, 2000. - С. 1-5.

9. Пат. РФ № 2025555. Подборщик подметальноуборочной машины / А. П.Свидинский, А. И. Стельмашенко, А. Г. Бобров. - Заявитель и патентообладатель - Научно-производственное объединение строительного и коммунального машиностроения «Стройкоммаш». Заявл. 03.06.1991; Опубл. 30.12.1994.-М. : ФИПС, 1994.- С. 1-4.

10. Пат. РФ № 2014136502. Пылезащитное устройство в строительстве / К. А. Трохимчук и др. Заявитель и патентообладатель - ВолГУ. - Заявл. 08.09.2014; Опубл.20.02.2015; Бюл. № 5. - М. : ФИПС, 2015. $-6 \mathrm{c}$.

11. Патент РФ № 2014113293/13. Пылегазовый аэродинамический узел для пылеуборочных машин / К.А. Трохимчук и др. Заявитель и патентообладатель - ВолГУ. - Заявл. 04.04.2014; Опубл. 20.10.2014; Бюл. № 29. - М. : ФИПС, 2000. - 6 с. 
12. Экология города : учебник / под ред. И. В. Стольберга. - Киев : Либра, 2000. - 213 с.

13. Энциклопедический словарь юного химика. - М. : Педагогика, 1990. - 320 с.

14. Янди, К. В. Смог над городом / К. В. Янди. М. : Стройиздат, 1978. - $109 \mathrm{c}$.

15. Яшек, Е. П. Промышленная пыль в городской среде (геохимические особенности и экологическая оценка) / Е. П. Яшек. - М. : ИМ ГРЭ, 2003. $82 \mathrm{c}$.

16. Barratt, B. Evaluation of the impact of dust suppressant application application on ambient PM 10 concentrations in London / King's College London, Environmental Research Group Prepared for Transport for London under contractto URS Infrastructure \& Environment Ltd. / B. Barratt, D. Carslaw, D. Green, G. Fuller, A. Tremper - London, Noyes Data Corp., 2012. - P. 234-286.

17. Directive 2008/50/EC of the European Parliament and of the Councul of 21 May 2008 on ambient air gualitu and cleaner air for Europe / Official Journal of the European Union (11.06.2008). - Hungary, Patent Office, 2008. - P. 1-4.

18. Extensive Dachbegrünung. Ergebnisse des Symposiums in der Technischen Universität Berlin. Berlin: M. Köhler, 1990. - 124 s.

19. Hupfer, P. Witterung und Klima / P. Hupfer, W. Kuttler. - Stuttgart, Leipzig : B.G. Teubner, 1998.$167 \mathrm{~s}$.

20. Köhler, M. Hof-, Fassaden- und Dachbegrünung Zentraler Baustein der Stadtökologie / M. Köhler, M. Schmidt. - Berlin, Maple, 1997. - 178 s.

21. Mackay, A.W. New approaches to characterizing urban air partickles in central London / A.W. Mackay, X. Long, N.L. Rose, R.W. Battarbee // J. Environ. Sei. (China). - Beijing, Publishing house «Cub», 1999. - №3. - P. 367-372.

\section{REFERENCES}

1. Azarov V.N., Yurkyan V.Yu., Sergina N.M. Metodika mikroskopicheskogo analiza dispersionnogo sostava pyli s primeneniem personal'nogo komp'jutera (PK) [A technique for microscopic analysis of the dispersion composition of dust using a personal computer (PC)], Zakonodatel'naja i prikladnaja metrologija [Legislative and applied metrology], 2004, no 1, pp. 46-48.

2. Belan, B.D. Himicheskij sostav atmosfernogo ajerozolja na razlichnyh vysotah/B.D. Belan, G.O. Zade, T.V. Kovalevskaja // Fotohimicheskie processy zemnoj atmosfery: St. nauch. trudov. Moskva, Nauka, 1990, pp. 5-12.

3. Gigienicheskie normativy GN 2.1.6.2604-10 «Predel'no dopustimye koncentracii (PDK) zagrjaznjajushhih veshhestv $\mathrm{v}$ atmosfernom vozduhe naselennyh mest». Moskva, Minzdrav Rossii, 2010, $61 \mathrm{~s}$.

4. Metodika mikroskopicheskogo analiza dispersnogo sostava pyli s primeneniem personal'nogo komp'jutera. St. Petersburg, OAO «NII Atmosfera», 2013, pp.15-17.

5. Metodika rascheta koncentracij $v$ atmosfernom vozduhe vrednyh veshhestv, soderzhashhihsja $\mathrm{v}$ vybrosah predprijatij: OND-86/ Goskomgidromet SSSR: Vved. (01.01.87)/St. Petersburg, Gidrometeoizdat, 1987, $91 \mathrm{~s}$.

6. Metodicheskoe posobie po raschetu vybrosov ot neorganizovannyh istochnikov $\mathrm{v}$ promyshlennosti stroitel'nyh materialov. Novorossijsk, ZAO «NIPIOTSTROM», 2002, $28 \mathrm{~s}$.

7. Pat. na poleznuju model’ RF № 32787. Mashina dlja uborki dorozhnyh pokrytij / Ju.I. Zav'jalov - Zajavitel' i patentoobladatel' - Obshhestvo s ogranichennoj otvetstvennost'ju "Planeta-K". Zajavl.14.05.2003; Opubl. 27.09. 2003. Moskva, FIPS, 2003, pp. 1-3.

8. Pat. RF №2147640. Mashina dlja ochistki tverdyh poverhnostej / V.A. Zakrevskij, V.B. Solomjanskij, D.M. Rostovcev - Zajavitel' i patentoobladatel' - Nauchnoproizvodstvennoe tovarishhestvo s ogranichennoj otvetstvennost'ju «Russkaja keramika». Zajavl. 17.02.1998; Opubl. 20.04.2000. Moskva, FIPS. 2000, pp. 1-5.

9. Pat. RF № 2025555. Podborshhik podmetal'no-uborochnoj mashiny /A.P.Svidinskij, A.I.Stel'mashenko, A.G.Bobrov. - Zajavitel' i patentoobladatel' - Nauchno-proizvodstvennoe obedinenie stroitel'nogo i kommunal'nogo mashinostroenija "Strojkommash". Zajavl. 03.06.1991; Opubl. 30.12.1994. Moskva, FIPS. 1994, pp. 1-4.

10. Pat. RF № 2014136502. Pylezashhitnoe ustrojstvo v stroitel'stve / K.A. Trohimchuk i dr.; Zajavitel' i patentoobladatel' - VolgGU. - Zajavl. 08.09.2014; Opubl.20.02.2015; Bjul. № 5. Moskva, FIPS. 2015, 6 s.

11. Patent RF № 2014113293/13. Pylegazovyj ajerodinamicheskij uzel dlja pyleuborochnyh mashin / K.A. Trohimchuk i dr.; Zajavitel' i patentoobladatel' VolgGU. - Zajavl. 04.04.2014; Opubl. 20.10.2014; Bjul. № 29. Moskva, FIPS. 2000, 6 s.

12. Jekologija goroda / Pod red. I.V. Stol'berga. Uchebnik. Kiev, «Libra», 2000, 213 s.

13. Jenciklopedicheskij slovar' junogo himika. Moskva, Pedagogika, 1990, $320 \mathrm{~s}$.

14. Jandi, K.V. Smog nad gorodom. Moskva, Strojizdat, 1978, 109 s.

15. Jashek, E.P.Promyshlennaja pyl'v gorodskoj srede (geohimicheskie osobennosti i jekologicheskaja ocenka). Moskva, IM GRJe, 2003, 82 s.

16. Barratt, B. Carslaw, D., Green, D., Fuller, G., Tremper, A. Evaluation of the impact of dust suppressant application application on ambient PM 10 concentrations in London /King's College London, Environmental 
К.А. Трохимчук. О влиянии промышленных предприятий на загрязненность мелкодисперсной пылью

Research Group Prepared for Transport for London under contractto URS Infrastructure \& Environment Ltd. London, Noyes Data Corp., 2012, pp. 234-286.

17. Directive 2008/50/EC of the European Parliament and of the Councul of 21 May 2008 on ambient air gualitu and cleaner air for Europe / Official Journal of the European Union (11.06.2008). Hungary, Patent Office, 2008, pp. 1-4.

18. Extensive Dachbegrünung. Ergebnisse des Symposiums in der Technischen Universität Berlin. Berlin, M. Köhler, 1990, 124 s.
19. Hupfer, P. Witterung und Klima/ P. Hupfer, W. Kuttler. Stuttgart, Leipzig: B.G. Teubner, 1998, $167 \mathrm{~s}$.

20. Köhler, M., Schmidt, M. Hof-, Fassaden- und Dachbegrünung Zentraler Baustein der Stadtökologie. Berlin, Maple, 1997, 178 s.

21. MackayA.W., Long X., Rose N.L., Battarbee R.W. New approaches to characterizing urban air partickles in central London // J. Environ. Sei. (China). - Beijing, Publishing house «Cub», 1999, no 3, pp. 367-372.

\section{Information about the Author}

Katerina A. Trokhimchuk, Candidate of Technical Sciences, Assistant Professor, Department of Ecology and Nature Management, Volgograd State University, Prosp. Universitetsky, 100, 400062 Volgograd, Russian Federation, tro232957@mail.ru.

\section{Информация об авторе}

Катерина Алексеевна Трохимчук, кандидат технических наук, старший преподаватель кафедры экологии и природопользования, Волгоградский государственный университет, просп. Университетский, 100, 400062 г. Волгоград, Российская Федерация, tro232957@mail.ru. 